\title{
Serum Adiponectin Levels Do Not Distinguish Primary from Metastatic Liver Tumors
}

\author{
SUSANNE FEDER $^{1}$, ARNE KANDULSKI ${ }^{1}$, DORIS SCHACHERER ${ }^{1}$, \\ THOMAS S. WEISS ${ }^{2}$ and CHRISTA BUECHLER ${ }^{1}$ \\ ${ }^{1}$ Department of Internal Medicine I, Regensburg University Hospital, Regensburg, Germany; \\ ${ }^{2}$ Children's University Hospital (KUNO), Regensburg University Hospital, Regensburg, Germany
}

\begin{abstract}
Background/Aim: Adiponectin protects from metabolic disease and cancer. Accordingly, serum adiponectin was reduced in patients with colorectal cancer $(C R C)$. This hepatoprotective factor was definitely increased in hepatocellular carcinoma (HCC). CRC metastases to the liver are common and the aim of the present study was to evaluate whether serum adiponectin discriminates primary from secondary liver cancers. Materials and Methods: Adiponectin was measured by ELISA in the serum of 36 patients with colorectal liver metastases, 32 patients with HCC and 49 patients without cancer. Results: Serum adiponectin levels were higher in cancer than non-tumor patients. Adiponectin was not related to TNM stage in HCC nor to the levels of serum tumor markers. Moreover, hepatic inflammation and liver fibrosis were not correlated with serum adiponectin levels. Metabolic diseases are associated with low adiponectin and a higher risk of cancer. In HCC, but not in CRC serum, adiponectin was increased in patients with hypertension and hyperuricemia. In this cohort, adiponectin positively correlated with chemerin, an adipokine supposed to contribute to metabolic disturbances. Conclusion: Serum adiponectin cannot discriminate primary from secondary liver tumors.
\end{abstract}

Adiponectin is a well-studied adipokine initially described by Arita et al. to circulate in very high concentrations and to be reduced in obesity $(1,2)$. Adiponectin improves insulin sensitivity, and has anti-inflammatory and hepatoprotective properties $(3,4)$. Insulin resistance, hypertension and dyslipidemia are common comorbidities of obese patients, and therefore, adiponectin reduction has been suggested to

Correspondence to: Christa Buechler, Regensburg University Hospital, Franz Josef Strauss Allee 11, Regensburg 93053 , Germany. Tel: +49 9419447009, e-mail: christa.buechler@ klinik.uni-regensburg.de

Key Words: Hypertension, chemerin, fibrosis, tumor marker. contribute to the metabolic syndrome (5). Circulating adiponectin levels were decreased in patients with obesity but were also lower in patients suffering from these complications (6). Hyperuricemia is associated with visceral adiposity, and serum adiponectin was also reduced in these patients (7).

Obesity is a risk factor for the development and progression of different cancers, such as hepatocellular carcinoma (HCC) and colorectal carcinoma (CRC) (8). Comorbidities associated with the metabolic syndrome further contribute to CRC and HCC vulnerability $(9,10)$. Low grade chronic inflammation and altered adipokine levels are supposed to play a causative role herein $(8,11)$. Risk of several cancers was indeed higher in patients with reduced adiponectin and this association was most relevant in endometrial, prostate, breast, colon, and gastroesophageal cancers (12). Accordingly, most studies have reported reduced serum adiponectin levels in patients with colorectal adenoma and CRC compared with healthy controls (13). In non-metastatic CRC, circulating adiponectin declined with tumor stage and was further associated with CRC recurrence (14). Protective activities of adiponectin in CRC were confirmed in experimental models where tumors were induced by chronic inflammation or implantation of colon cancer cells $(15,16)$. Current evidence from clinical and experimental studies support the idea that low adiponectin levels contribute to disease initiation, progression and prognosis of CRC $(11,12)$.

Beneficial effects of adiponectin were further identified in models of alcoholic and non-alcoholic liver diseases $(2,17$, 18). Later on, it was found that serum adiponectin was induced in patients with advanced liver injury (19). This was partly attributed to an impaired biliary secretion of adiponectin in patients with chronic liver diseases $(11,20)$. High adiponectin levels were furthermore associated with an increased risk to develop $\operatorname{HCC}(11,21)$. In patients with $\mathrm{HCC}$, circulating levels of this adipokine were elevated and, in some cohorts, independently predicted overall survival $(11,21-24)$. 
Experimental studies demonstrated a protective role of adiponectin in liver cirrhosis and HCC (25-27). High adiponectin levels in patients with liver cirrhosis and/or HCC were linked to disease progression $(11,19)$. Low expression of adiponectin receptors in liver tumors points to a state of adiponectin resistance in these patients (28).

CRC metastases are commonly detected in the liver (29). Here, we hypothesized that patients with colorectal liver metastases have lower serum adiponectin levels compared to patients with HCC. Therefore, adiponectin was measured in the serum of both cohorts.

\section{Materials and Methods}

Patient cohorts. Patients and non-tumor controls used in the present study have been described recently in detail (30). Anthropometric and laboratory data of the patients are shown in Table I of this freely accessible paper (30).

The liver of the patients was histologically examined and scored as suggested by Kleiner et al. (31). HCC staging was performed as described (32). Prospective collection of CRC patients' serum was done from January 2012 to June 2015, and of HCC patients' serum from May 2012 to May 2015. Inclusion criteria were: 1) histologically confirmed HCC or CRC metastases and 2) age above 18 years. Exclusion criteria was pregnancy.

Serum of controls without tumors was obtained from January 2008 to June 2008. The cohort included hospitalized patients and outdoor patients. These patients were referred to the Interdisciplinary Ultrasound Department of the Hospital and were described recently $(33,34)$. The study cohort included 56 patients and serum from 49 patients was available for the present study. Patients with malignancies, inflammatory bowel disease, ascites, hepatobiliary diseases, familial hyperlipidemia, drugs that cause hepatic steatosis, infection with HIV, chronic drug or alcohol abuse, and acute medical conditions with confounding effect on laboratory values were excluded from the study. Aliquots of the sera were stored at $-80^{\circ} \mathrm{C}$ to avoid freeze-thaw cycles. Storage time of serum differed for up to 7 years. This may limit the relevance of the findings of our study. There was, however, no difference in serum adiponectin levels of patients with CRC, which were collected in 2012 (6 patients) and 2015 (10 patients; $p=0.18)$. This indicates that a four-year storage period at $-80^{\circ} \mathrm{C}$ did not grossly diminish serum adiponectin levels. A further study showed that frozen storage of plasma at $-30^{\circ} \mathrm{C}$ for 30 months had no effect on adiponectin levels (35). Thus, the changes in adiponectin levels during seven-year storage may be rather small.

Experiments complied with the guidelines of the charitable statecontrolled foundation Human Tissue and Cell Research, Germany. Each patient signed a written informed consent. The study was approved by the ethical committee of the Regensburg University Hospital.

Adiponectin ELISA. Adiponectin ELISA was purchased from R\&D Systems (Wiesbaden, Germany) and performed as recommended by the manufacturer. Serum was diluted 1:5,000 fold before analysis.

Laboratory value. Metabolites such as bilirubin, aminotransferases and tumor markers were routinely measured at the Institute for Clinical Chemistry and Laboratory Medicine (University Hospital Regensburg).
Table I. Correlations of adiponectin with tumor markers and measures of liver disease in the whole cohort of cancer patients and the subgroups.

\begin{tabular}{|c|c|c|c|}
\hline Laboratory value & Whole cohort & $\mathrm{HCC}$ & $\mathrm{CRC}$ \\
\hline \multirow[t]{2}{*}{ AFP } & $\mathrm{r}=-0.067$ & $\mathrm{r}=-0.163$ & $\mathrm{r}=0.300$ \\
\hline & $p=0.680$ & $p=0.436$ & $p=0.277$ \\
\hline \multirow[t]{2}{*}{ CEA } & $\mathrm{r}=-0.049$ & $\mathrm{r}=-0.202$ & $\mathrm{r}=0.079$ \\
\hline & $p=0.728$ & $p=0.392$ & $p=0.667$ \\
\hline \multirow[t]{2}{*}{ CA19-9 } & $\mathrm{r}=-0.037$ & $\mathrm{r}=-0.274$ & $\mathrm{r}=0.007$ \\
\hline & $p=0.798$ & $p=0.257$ & $p=0.969$ \\
\hline \multirow[t]{2}{*}{ Prothrombin time (s) } & $\mathrm{r}=0.004$ & $\mathrm{r}=-0.085$ & $\mathrm{r}=0.038$ \\
\hline & $p=0.978$ & $p=0.654$ & $p=0.827$ \\
\hline \multirow[t]{2}{*}{ Bilirubin (mg/dl) } & $r=-0.267$ & $\mathrm{r}=-0.158$ & $r=-0.371$ \\
\hline & $p=\mathbf{0 . 0 3 0}$ & $p=0.395$ & $p=0.028$ \\
\hline \multirow[t]{2}{*}{ Alanine aminotransferase (U/l) } & $\mathrm{r}=-0.207$ & $\mathrm{r}=-0.153$ & $\mathrm{r}=-0.275$ \\
\hline & $p=0.101$ & $p=0.420$ & $p=0.116$ \\
\hline \multirow[t]{2}{*}{ Aspartate aminotransferase (U/l) } & $\mathrm{r}=-0.014$ & $\mathrm{r}=0.180$ & $\mathrm{r}=-0.157$ \\
\hline & $p=0.911$ & $p=0.333$ & $p=0.374$ \\
\hline \multirow[t]{2}{*}{$\gamma$-Glutamyltransferase (U/l) } & $\mathrm{r}=0.032$ & $\mathrm{r}=0.344$ & $\mathrm{r}=-0.130$ \\
\hline & $p=0.807$ & $p=0.079$ & $p=0.472$ \\
\hline
\end{tabular}

Correlation coefficient $r$ and $p$-values are shown. Significant correlations and p-values are in bold. HCC, Hepatocellular carcinoma; CRC, colorectal cancer; AFP, alpha-fetoprotein; CEA, carcinoembryonic antigen; CA19-9, cancer antigen 19-9.

Statistics. Results are shown as box plots, which indicate the median values, lower and upper quartiles and the range. The points in the graphs indicate outliers, which are values outside of the inner fences. The stars mark extreme outliers where the values were more than 3-times the height of the boxes. Statistical tests used were Mann-Whitney $U$-Test, Spearman correlation and one-way Anova with post-hoc Bonferroni (SPSS Statistics 25.0 program). A value of $p<0.05$ was regarded as significant.

\section{Results}

Association of serum adiponectin levels with gender, age and BMI. Adiponectin was measured in serum samples of 49 control patients without any tumors, $32 \mathrm{HCC}$ and $36 \mathrm{CRC}$ patients with liver metastases by ELISA. Controls were patients who came to the hospital mainly due to stomach or epigastric pain, but without any cancers.

As expected, HCC patients had increased aminotransferase activities (36) and higher levels of $\gamma$-glutamyltransferase (30). The tumor marker alpha-fetoprotein (AFP) tended to be higher in HCC $(p=0.065)$, whereas carcinoembryonic antigen (CEA) and cancer antigen 19-9 (CA 19-9) were significantly increased in CRC patients (30).

Higher adiponectin levels were detected in female non-tumor ( $p=0.018$ ) and tumor-bearing patients (Figure 1A). In the three cohorts, adiponectin levels did not correlate with age (data not shown). Negative association with BMI was identified in the non-tumor patients only $(\mathrm{r}=-0.367, p=0.01)$. Accordingly, 

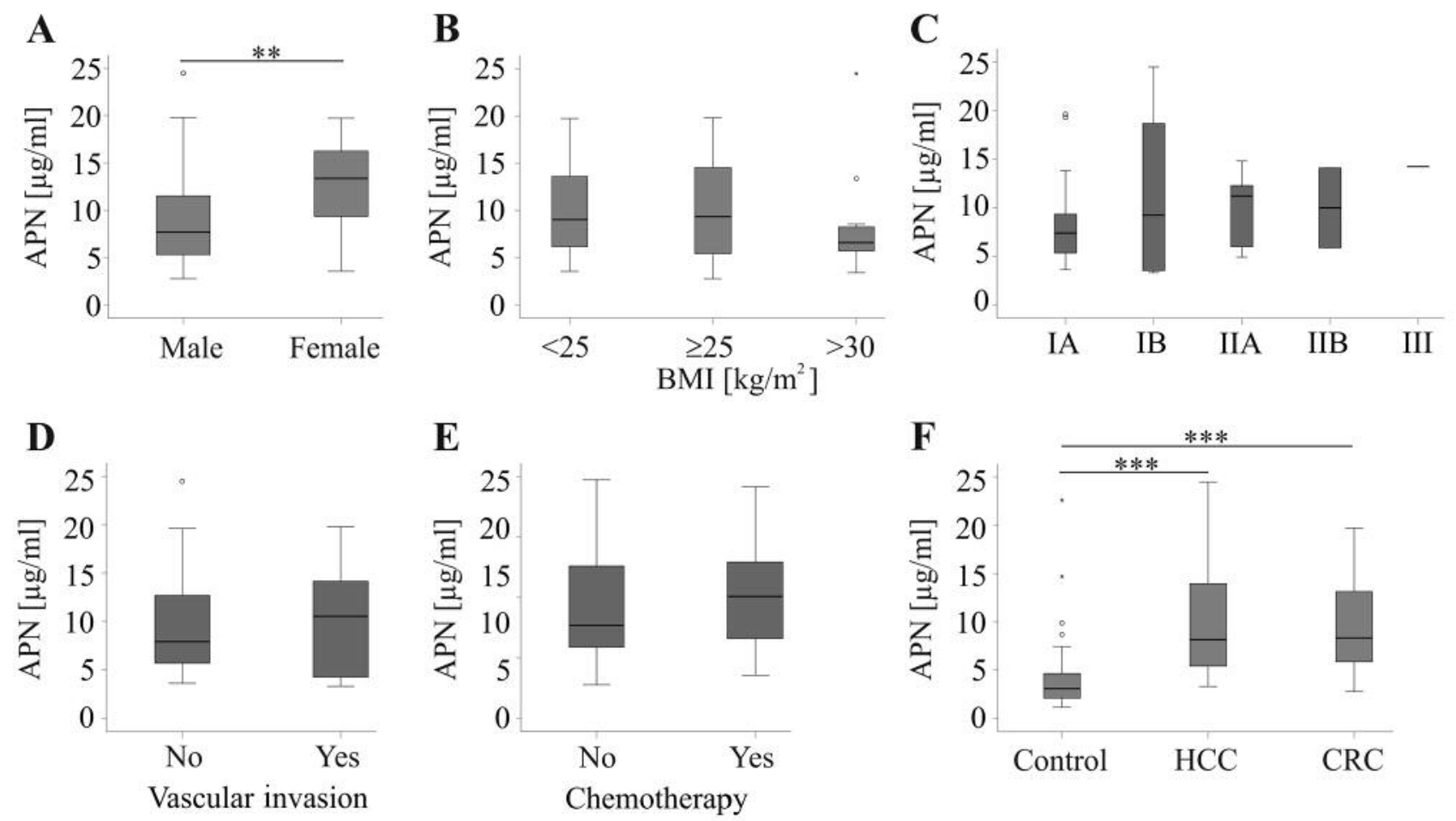

Figure 1. Adiponectin (APN) in the serum of patients with hepatocellular carcinoma (HCC), colorectal carcinoma (CRC) and non-tumor patients (Control). (A) APN in the serum of 51 male and 17 female tumor patients. (B) Serum APN stratified for body mass index (BMI) in the tumor patients. There were 24,32 , and 11 patients with a $B M I<25, \geq 25$ and $>30 \mathrm{~kg} / \mathrm{m}^{2}$, respectively. BMI of 1 patient is not known. (C) APN relative to TNM stage in HCC patients (TNM stage: IA/IB/IIA/IIB/III, number of patients 14/8/7/2/1 per stage) (D) APN in 20 HCC patients without and 12 HCC patients with vascular invasion. (E) APN in 13 CRC patients with and 23 CRC patients without chemotherapy. (F) APN in 32 HCC, 36 CRC and 49 non-tumor controls. $* * p<0.01, * * * p<0.001$.

adiponectin was similar in normal-weight, overweight and obese tumor patients (Figure 1B). This was also the case when both cohorts were analyzed separately (data not shown).

Association of serum adiponectin levels with tumor-nodemetastasis (TNM) stage, tumor markers and tumor type. In the HCC group, adiponectin was not correlated with tumor size $(\mathrm{r}=0.169, p=0.355)$, grade $(\mathrm{r}=-0.039, p=0.841)$ or TNM stage (Figure 1C). Patients with and without vascular invasion had similar serum adiponectin levels (Figure 1D). Serum of CRC patients was collected shortly before hepatic resection of the metastases, whereas the primary tumor was discovered up to six years earlier. Therefore, associations of adiponectin with tumor stage/grade were not calculated.

In the cohort of CRC patients, there were 13 patients who received neoadjuvant chemotherapy before liver resection. Adiponectin did not differ in this cohort (Figure 1E).

Adiponectin did not correlate with the tumor markers AFP, CA 19-9 or CEA (Table I).

Relative to the controls, adiponectin levels were higher in HCC and CRC patients with no differences between the two cohorts of cancer patients (Figure 1F).
Association of serum adiponectin levels with comorbidities. Reduced serum adiponectin levels in patients with type 2 diabetes, hypertension, hypercholesterolaemia and hyperuricaemia are well-described in the literature $(6,7)$. In the non-tumor cohort, adiponectin was lower in the type 2 diabetic patients $(p=0.011)$, but was not changed in patients with hypercholesterinemia $(p=0.587)$ or hypertension $(p=0.488)$ (data not shown). In the tumor-bearing patients, adiponectin levels were, however, not changed in the 21 patients with type 2 diabetes. Adiponectin was not significantly diminished in the 34 patients with arterial hypertension $(p=0.079)$. Moreover, hypercholesterolaemia (11 patients) and hyperuricaemia (7 patients) were not associated with reduced circulating adiponectin levels (data not shown).

Separate analysis of the cohort of CRC patients revealed similar results; serum adiponectin levels were not changed with comorbidities ( 6 type 2 diabetic patients, 8 patients with hypercholesterolemia, 16 with hypertension and 3 with hyperuricemia; Figure $2 \mathrm{~A}-\mathrm{C}$ and data not shown). In the cohort of HCC patients, the 15 type 2 diabetes patients and the 3 hypercholesterolaemic patients had adiponectin levels comparable to those without this comorbidities (Figure 2D 

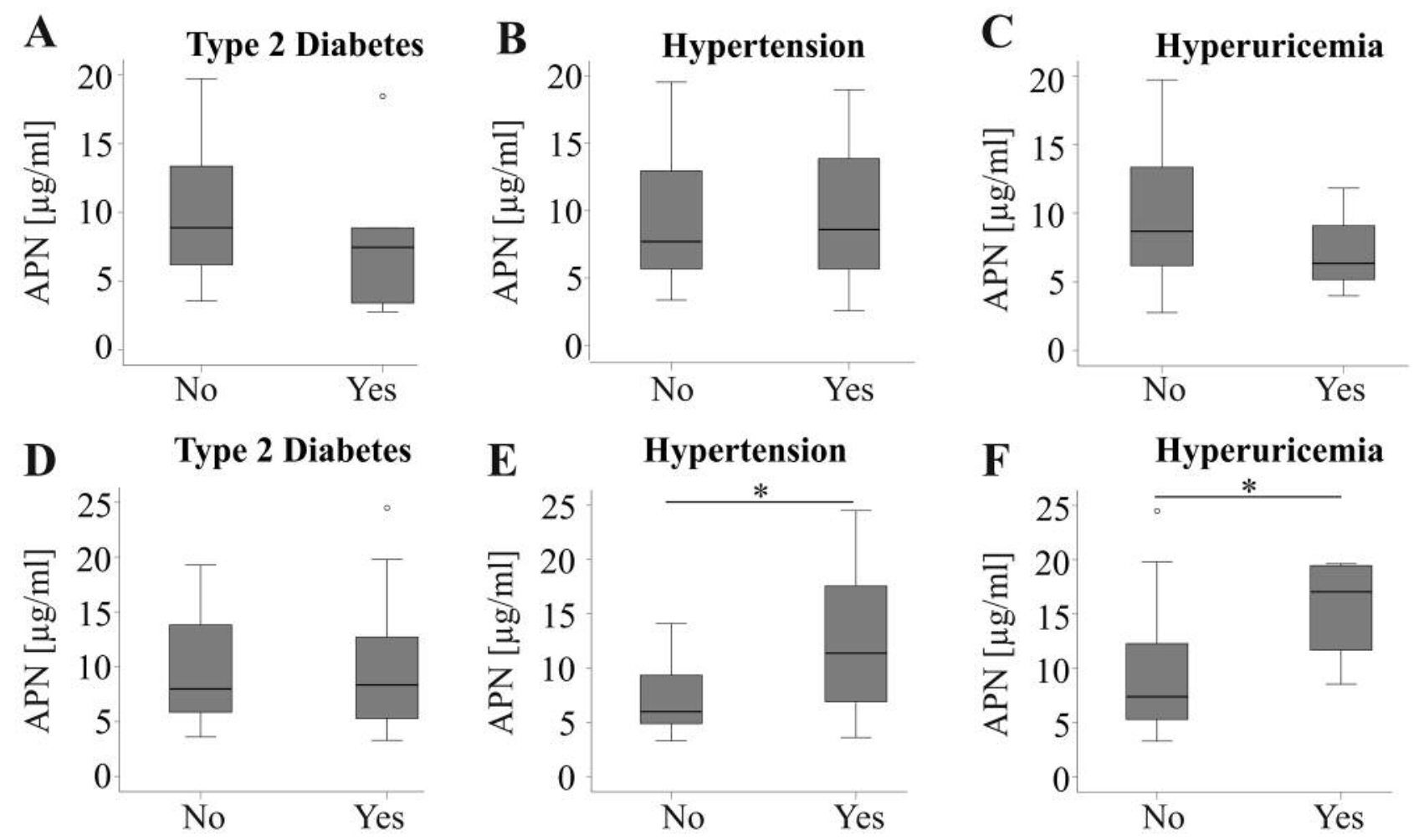

Figure 2. Serum adiponectin (APN) and comorbidities. (A) APN in 6 colorectal cancer (CRC) patients with and 30 patients without type 2 diabetes. (B) APN in 16 CRC patients with and 20 patients without hypertension. (C) APN in 3 CRC patients with and 33 patients without hyperuricemia. (D) APN in 15 hepatocellular carcinoma (HCC) patients with and 17 patients without type 2 diabetes. (E) APN in 18 HCC patients with and 14 patients without hypertension. (F) APN in 4 HCC patients with and 28 patients without hyperuricemia. $* p<0.05$.

and data not shown). Serum adiponectin was unexpectedly increased in the 18 patients with arterial hypertension and the 4 hyperuricemic patients (Figure 2E, F).

Association of adiponectin with liver dysfunction. Serum adiponectin did not correlate with levels of alanine aminotransferase, aspartate aminotransferase, $\gamma$-glutamyltransferase or prothrombin time in the whole cohort, and when CRC patients and HCC patients were analyzed separately (Table I). A modest negative association with bilirubin was identified in the whole study group and in CRC, but not in HCC patients (Table I).

We furthermore analyzed potential associations of serum adiponectin with histologic liver abnormalities. The histological results in the cohort of HCC patients showed that 16 patients had liver steatosis, 18 patients had predominant inflammatory conditions and 23 patients had liver fibrosis. In the CRC cohort, hepatic steatosis was identified in 17 patients, liver inflammation in 13 patients and liver fibrosis in 17 patients. Prevalence of these histologic features was comparable in both cohorts of tumor patients.
Serum adiponectin was negatively related to steatosis grade (Figure $3 \mathrm{~A}$ ), but was not significantly changed in patients without or with fatty liver (Figure 3B). Serum adiponectin did not correlate with inflammation or fibrosis scores (data not shown). Accordingly, serum adiponectin did not change with the extent of inflammation or fibrosis in the whole study group (Figure 3C, D), and when both cohorts were analyzed seperately (data not shown).

Correlation of adiponectin with serum chemerin. Chemerin is an adipokine, which is induced in obesity and is positively associated with dyslipidemia and hypertension (37, 38). A negative correlation of chemerin and adiponectin was detected in non-diabetic obese patients (39). However, adiponectin did not correlate with chemerin in the non-tumor patients analyzed in the present study $(\mathrm{r}=0.238, p=0.099)$. Of note, a positive correlation of serum adiponectin and chemerin was identified in the whole study group of cancer patients. Significant association of these adipokines was seen in HCC but not in CRC patients (Figure 4A-C). 
A
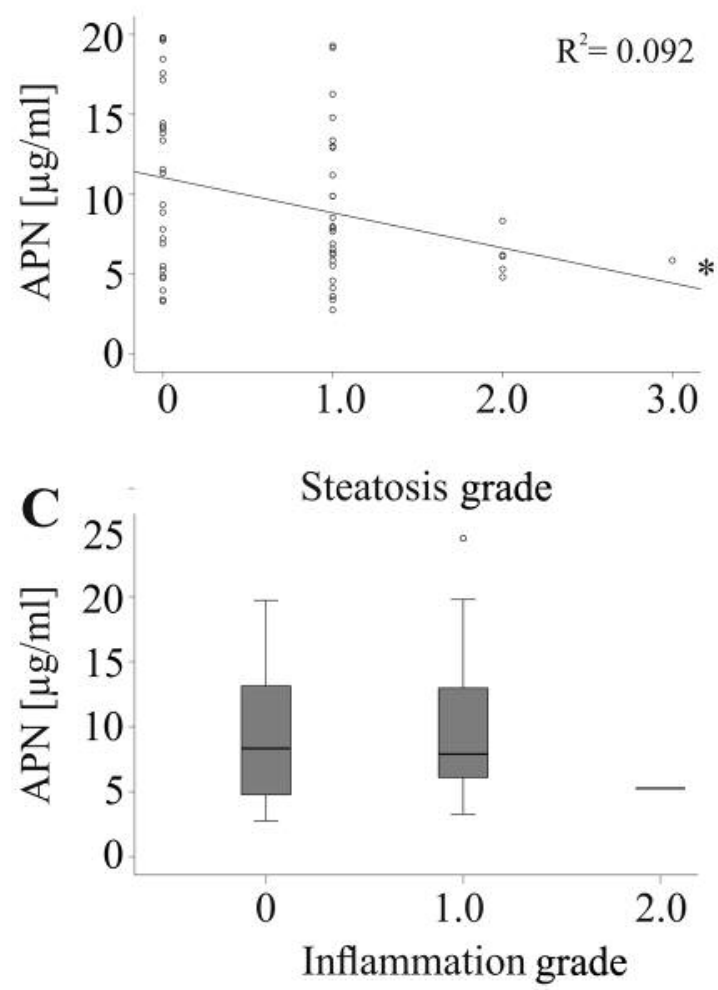

B
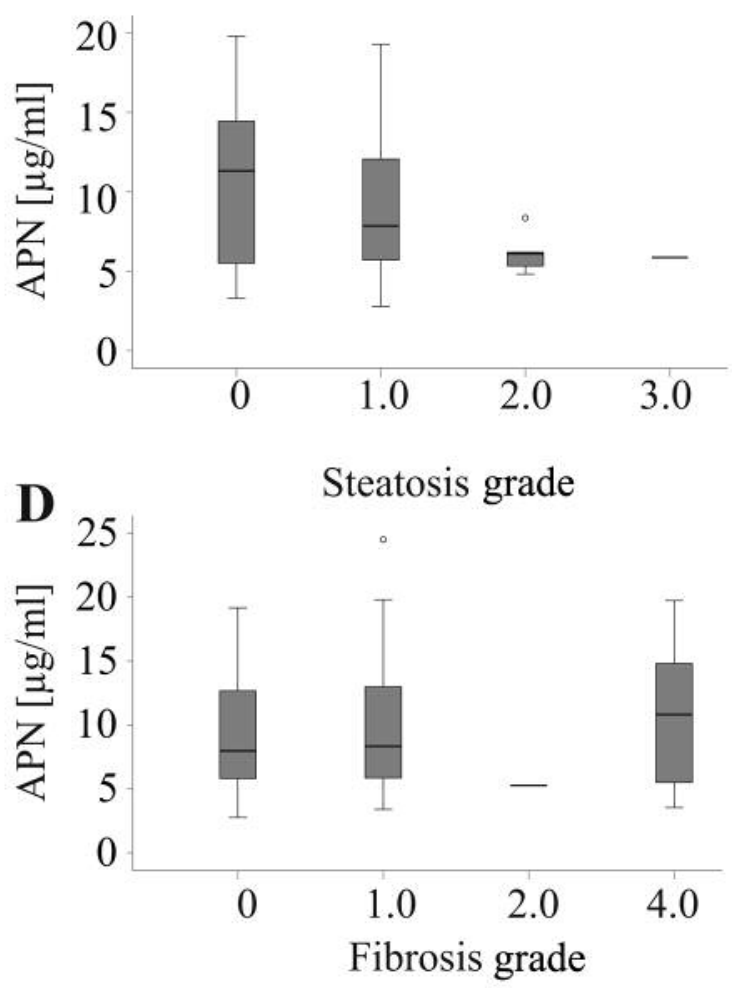

Figure 3. Serum adiponectin (APN) and liver injury. (A) Correlation of APN with steatosis grade. (B) APN in patients stratified for hepatic steatosis (25 patients without steatosis (0), 27 patients with grade 1, 5 patients with grade 2 and 1 patient with grade 3; Steatosis grade was not documented in 10 patients). (C) APN in patients stratified for hepatic inflammation (28 patients had no inflammation (0), 29 patients had grade 1 and 1 patient had grade 2; Data of 9 patients were not known). (D) APN in patients stratified for hepatic fibrosis (28 patients had no fibrosis, 25 patients had grade 1, 1 patient had grade 2 and 14 patients grade 4). Statistical test is not valid for groups with 1 patient.

\section{Discussion}

The main findings of our study were the comparable serum adiponectin levels in patients with $\mathrm{HCC}$ and colorectal liver metastases. Though serum adiponectin was induced in tumorbearing patients when compared to non-tumor controls, its levels were not related to systemic tumor markers or HCC staging. The described negative correlations of adiponectin with hypertension and hyperuricemia in non-tumor patients $(6$, 7) were abolished in CRC patients. In the HCC cohort, patients with these comorbidities indeed had increased adiponectin levels. Furthermore, serum adiponectin levels were not related to histologically evaluated liver injury.

HCC mostly develops in the cirrhotic liver (40), and these patients had high serum adiponectin levels at an advanced disease stage (19). Such an induced adiponectin level was not identified in the tumor patients. Taking into account that the few of the enrolled cirrhotic patients had compensated liver disease this is in accordance with previous studies (19).
HCC did not change serum adiponectin levels in hepatitis $\mathrm{C}$ virus infected patients (41). Moreover, cirrhotic and noncirrhotic HCC patients had serum adiponectin levels similar to those of the correponding controls (23). However, high serum adiponectin predicted the risk of HCC development in patients with chronic hepatitis C (21), and has been associated with worse overall survival in HCC patients with different disease etiologies (42). Moreover, increased adiponectin has been identified in HCC patients in comparison to a cohort of matched non-tumor patients and controls (43). Similarly, adiponectin was induced in the cohort of HCC patients when compared to non-tumor patients in the present study. However, unexpectedly, CRC patients with metastases had adiponectin levels comparable to HCC patients. Though separate studies have described a decline of serum adiponectin in CRC patients $(14,44)$, a further analysis has shown normalization of serum adiponectin in patients with advanced disease (45). Thus, adiponectin is actually induced in CRC patients with liver 

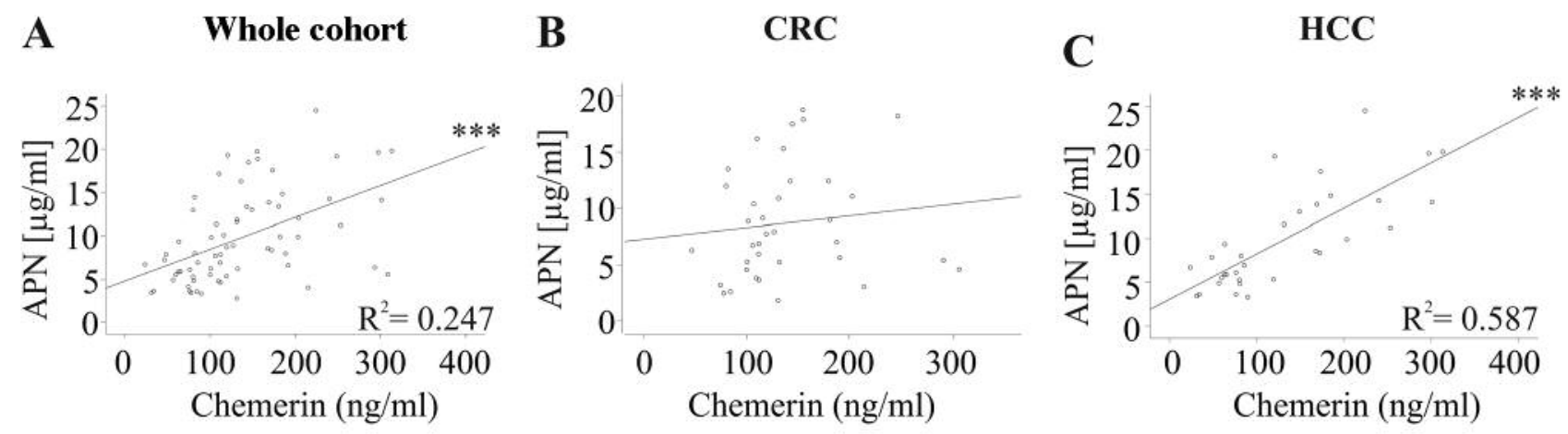

Figure 4. Correlation of serum adiponectin $(A P N)$ and chemerin. Correlation of $A P N$ and chemerin in $(A)$ all tumor patients $(B)$ in colorectal cancer (CRC) and (C) hepatocellular carcinoma (HCC) patients. ${ }^{* *} p<0.001$.

metastases. This suggestion has to be confirmed in CRC patients with and without metastatic disease.

To our knowledge, serum adiponectin levels have not been compared in patients with primary and secondary liver cancers. Here, similar serum levels were found in CRC patients with liver metastases and HCC.

A major advantage of our study is the analysis of associations of serum adiponectin levels with marked changes in liver histology and clinical data of liver function. Serum adiponectin showed a very modest and negative association with liver steatosis. Such correlations have been described before in different patient cohorts $(2,46)$. Adiponectin did not, however, correlate with hepatic inflammation or fibrosis. Actually, adiponectin levels were not higher in cirrhotics with compensated disease than patients without or with mild liver fibrosis.

Positive associations of adiponectin with the extent of liver fibrosis and negative correlations with hepatic steatosis have been nevertheless described in hepatitis $\mathrm{C}$ infected patients $(47,48)$. In NAFLD, serum adiponectin has been inversely associated with the severity of liver steatosis and fibrosis (49). Another study has confirmed our results that adiponectin did not correlate with fibrosis stage (50). Thus, associations between serum adiponectin and liver fibrosis stages need possibly also to be discussed in relation to the underlying disease. Modest positive correlations of adiponectin with bilirubin were only identified in CRC patients. This indicates that association of serum adiponectin with this cholestasis marker is modified by disease etiology.

Characteristics of the metabolic status of a patient such as BMI, insulin resistance and comorbidities may further affect circulating adiponectin levels $(2,4)$. Adiponectin has been found to be reduced in insulin resistance (2). Negative correlations with homeostasis model assessment (HOMA) index have also been identified in patients with chronic liver injury, whereas further studies could not detect any associations with this measure $(22,24,51)$. Of note, adiponectin has not been associated with BMI and HOMA index in patients with progressed liver cirrhosis $(50,52)$. In CRC patients low adiponectin has been linked to insulin resistance (53). In our cohort analyzing patients with HCC and $\mathrm{CRC}$, serum adiponectin levels were not related to BMI and were not altered in type 2 diabetes. Similar studies in cohorts with cancer patients have demonstrated that serum adiponectin did not negatively correlate with BMI, dyslipidemia or insulin resistance $(22,54,55)$. Well known negative correlations of adiponectin with BMI and insulin resistance $(2,4)$ were thus abolished in $\mathrm{HCC}$ and $\mathrm{CRC}$ patients $(22,54)$.

Of note, the present analysis showed that adiponectin was actually induced in HCC patients with hypertension and hyperuricemia. Comorbidities are in general and possibly by definition more prevalent in cohorts of tumor patients than healthy controls $(9,10)$. Elevated adiponectin described in HCC cohorts may thus be related to these complications (22). Unchanged and even increased serum adiponectin levels in cancer patients suffering from these comorbities further showed that associations described in the general population were either lost or even reversed in tumor patients $(6,7)$.

Chemerin is abundant in adipocytes and hepatocytes and circulating chemerin levels were increased in obese patients (37). Previous studies have reported that circulating chemerin was not changed in HCC serum whereas its levels were induced in CRC patients $(19,56,57)$. Our recent study showed comparable chemerin levels in the HCC and CRC patients with liver metastases (30). Here, we demonstrated a positive correlation of serum chemerin with adiponectin in HCC but not in patients with CRC. In non-cancer patients, negative correlations of these two adipokines has been described (58), illustrating the dysregulated balance of these two metabolic active proteins, especially in patients with HCC. In summary, the present study demonstrated 
comparable serum adiponectin levels in patients with HCC and colorectal liver metastases. Positive associations of serum adiponectin with comorbidities and serum chemerin were identified in HCC but not in CRC patients, suggesting a specific function of this adipokine in the pathogenetic sequence of liver disease.

\section{Funding}

This research was partly funded by the German Research Foundation, grant number BU 1141/13-1.

\section{Conflicts of Interest}

The Authors report no conflicts of interest regarding this work.

\section{Authors' Contributions}

Conceptualization: C.B., T.S.W., A.K.; methodology: S.F.; software: formal analysis, S.F., C.B.; resources: T.S.W., D.S.; writing original draft preparation: C.B.; writing - review and editing: C.B., S.F., D.S., A.K., T.S.W.

\section{Acknowledgements}

The excellent technical assistance of Elena Underberg is greatly acknowledged.

\section{References}

1 Arita Y, Kihara S, Ouchi N, Takahashi M, Maeda K, Miyagawa J, Hotta K, Shimomura I, Nakamura T, Miyaoka K, Kuriyama H, Nishida M, Yamashita S, Okubo K, Matsubara K, Muraguchi $\mathrm{M}$, Ohmoto $\mathrm{Y}$, Funahashi $\mathrm{T}$ and Matsuzawa Y: Paradoxical decrease of an adipose-specific protein, adiponectin, in obesity. Biochem Biophys Res Commun 257: 79-83, 1999. PMID: 10092513. DOI: 10.1006/bbrc.1999.0255

2 Buechler C, Wanninger J and Neumeier M: Adiponectin, a key adipokine in obesity related liver diseases. World J Gastroenterol 17: 2801-2811, 2011. PMID: 21734787. DOI: 10.3748/wjg.v17. i23.2801

3 Iwabu M, Okada-Iwabu M, Yamauchi $\mathrm{T}$ and Kadowaki T: Adiponectin/adiponectin receptor in disease and aging. NPJ Aging Mech Dis 1: 15013, 2015. PMID: 28721260. DOI: 10.1038/npjamd.2015.13

4 Wang ZV and Scherer PE: Adiponectin, the past two decades. J Mol Cell Biol 8: 93-100, 2016. PMID: 26993047. DOI: 10.1093/jmcb/mjw011

5 Khaodhiar L, McCowen KC and Blackburn GL: Obesity and its comorbid conditions. Clin Cornerstone 2: 17-31, 1999. PMID: 10696282.

6 Brooks NL, Moore KS, Clark RD, Perfetti MT, Trent CM and Combs TP: Do low levels of circulating adiponectin represent a biomarker or just another risk factor for the metabolic syndrome? Diabetes Obes Metab 9: 246-258, 2007. PMID: 17391150. DOI: 10.1111/j.1463-1326.2006.00596.x

7 Tamba S, Nishizawa H, Funahashi T, Okauchi Y, Ogawa T, Noguchi M, Fujita K, Ryo M, Kihara S, Iwahashi H, Yamagata
K, Nakamura T, Shimomura I and Matsuzawa Y: Relationship between the serum uric acid level, visceral fat accumulation and serum adiponectin concentration in Japanese men. Intern Med 47: 1175-1180, 2008. PMID: 18591837.

8 Kern L, Mittenbuhler MJ, Vesting AJ, Ostermann AL, Wunderlich CM and Wunderlich FT: Obesity-induced TNFalpha and IL-6 Signaling: The missing link between obesity and inflammationdriven liver and colorectal cancers. Cancers (Basel) 11: 2018. PMID: 30591653. DOI: 10.3390/cancers11010024

9 Ishino K, Mutoh M, Totsuka Y and Nakagama H: Metabolic syndrome: a novel high-risk state for colorectal cancer. Cancer Lett 334: 56-61, 2013. PMID: 23085010. DOI: 10.1016/j.canlet. 2012.10.012

10 Rahman R, Hammoud GM, Almashhrawi AA, Ahmed KT and Ibdah JA: Primary hepatocellular carcinoma and metabolic syndrome: An update. World J Gastrointest Oncol 5: 186-194, 2013. PMID: 24069511. DOI: 10.4251/wjgo.v5.i9.186

11 Wieser V, Moschen AR and Tilg H: Adipocytokines and hepatocellular carcinoma. Dig Dis 30: 508-513, 2012. PMID: 23108307. DOI: $10.1159 / 000341702$

12 Wei T, Ye P, Peng X, Wu LL and Yu GY: Circulating adiponectin levels in various malignancies: an updated meta-analysis of 107 studies. Oncotarget 7: 48671-48691, 2016. PMID: 27119501. DOI: 10.18632 /oncotarget.8932

13 An W, Bai Y, Deng SX, Gao J, Ben QW, Cai QC, Zhang HG and Li ZS: Adiponectin levels in patients with colorectal cancer and adenoma: a meta-analysis. Eur J Cancer Prev 21: 126-133, 2012. PMID: 21960184. DOI: 10.1097/CEJ.0b013e32834c9b55

14 Ferroni P, Palmirotta R, Spila A, Martini F, Raparelli V, Fossile E, Mariotti S, Del Monte G, Buonomo O, Roselli $\mathrm{M}$ and Guadagni F: Prognostic significance of adiponectin levels in non-metastatic colorectal cancer. Anticancer Res 27: 483-489, 2007. PMID: 17348431.

15 Moon HS, Liu X, Nagel JM, Chamberland JP, Diakopoulos KN, Brinkoetter MT, Hatziapostolou M, Wu Y, Robson SC, Iliopoulos D and Mantzoros CS: Salutary effects of adiponectin on colon cancer: in vivo and in vitro studies in mice. Gut 62: 561-570, 2013. PMID: 22735569. DOI: 10.1136/gutjnl-2012302092

16 Saxena A, Chumanevich A, Fletcher E, Larsen B, Lattwein K, Kaur K and Fayad R: Adiponectin deficiency: role in chronic inflammation induced colon cancer. Biochim Biophys Acta 1822: 527-536, 2012. PMID: 22198319. DOI: 10.1016/j.bbadis.2011. 12.006

17 Adolph TE, Grander C, Grabherr F and Tilg H: Adipokines and non-alcoholic fatty liver disease: multiple interactions. Int J Mol Sci 18: 2017. PMID: 28758929. DOI: 10.3390/ijms 18081649

18 Tilg H: The role of cytokines in non-alcoholic fatty liver disease. Dig Dis 28: 179-185, 2010. PMID: 20460908. DOI: 10.1159/ 000282083

19 Buechler C, Haberl EM, Rein-Fischboeck L and Aslanidis C: Adipokines in Liver Cirrhosis. Int J Mol Sci 18: 2017. PMID: 28661458. DOI: 10.3390/ijms 18071392

20 Halberg N, Schraw TD, Wang ZV, Kim JY, Yi J, Hamilton MP, Luby-Phelps K and Scherer PE: Systemic fate of the adipocytederived factor adiponectin. Diabetes 58: 1961-1970, 2009. PMID: 19581422. DOI: $10.2337 / \mathrm{db} 08-1750$

21 Arano T, Nakagawa H, Tateishi R, Ikeda H, Uchino K, Enooku K, Goto E, Masuzaki R, Asaoka Y, Kondo Y, Goto T, Shiina S, Omata M, Yoshida H and Koike K: Serum level of adiponectin 
and the risk of liver cancer development in chronic hepatitis $\mathrm{C}$ patients. Int J Cancer 129: 2226-2235, 2011. PMID: 21170963. DOI: $10.1002 / \mathrm{ijc} .25861$

22 Chen MJ, Yeh YT, Lee KT, Tsai CJ, Lee HH and Wang SN: The promoting effect of adiponectin in hepatocellular carcinoma. J Surg Oncol 106: 181-187, 2012. PMID: 22287480. DOI: $10.1002 /$ jso. 23059

23 Sadik NA, Ahmed A and Ahmed S: The significance of serum levels of adiponectin, leptin, and hyaluronic acid in hepatocellular carcinoma of cirrhotic and noncirrhotic patients. Hum Exp Toxicol 31: 311-321, 2012. PMID: 22249387. DOI: 10.1177/0960327111431091

24 Arano T, Nakagawa H, Ikeda $\mathrm{H}$ and Koike K: Adiponectin in chronic hepatitis C. Clin J Gastroenterol 6: 259-263, 2013. PMID: 26181728. DOI: 10.1007/s12328-013-0410-1

25 Kamada Y, Matsumoto H, Tamura S, Fukushima J, Kiso S, Fukui K, Igura T, Maeda N, Kihara S, Funahashi T, Matsuzawa Y, Shimomura I and Hayashi N: Hypoadiponectinemia accelerates hepatic tumor formation in a nonalcoholic steatohepatitis mouse model. J Hepatol 47: 556-564, 2007. PMID: 17459514. DOI: 10.1016/j.jhep.2007.03.020

26 Saxena NK, Fu PP, Nagalingam A, Wang J, Handy J, Cohen C, Tighiouart M, Sharma D and Anania FA: Adiponectin modulates $\mathrm{C}$-jun N-terminal kinase and mammalian target of rapamycin and inhibits hepatocellular carcinoma. Gastroenterology 139: 1762-1773, 1773.e1-5, 2010. PMID. 20637208. DOI: 10.1053/ j.gastro.2010.07.001

27 Sharma D, Wang J, Fu PP, Sharma S, Nagalingam A, Mells J, Handy J, Page AJ, Cohen C, Anania FA and Saxena NK: Adiponectin antagonizes the oncogenic actions of leptin in hepatocellular carcinogenesis. Hepatology 52: 1713-1722, 2010. PMID: 20941777. DOI: 10.1002/hep.23892

28 Shin E, Yu YD, Kim DS and Won NH: Adiponectin receptor expression predicts favorable prognosis in cases of hepatocellular carcinoma. Pathol Oncol Res 20: 667-675, 2014. PMID: 24619866. DOI: 10.1007/s12253-014-9747-0

29 Milette S, Sicklick JK, Lowy AM and Brodt P: Molecular pathways: Targeting the microenvironment of liver metastases. Clin Cancer Res 23: 6390-6399, 2017. PMID: 28615370. DOI: 10.1158/1078-0432.CCR-15-1636

30 Feder S, Kandulski A, Schacherer D, Weiss TS and Buechler C: Serum chemerin does not differentiate colorectal liver metastases from hepatocellular carcinoma. Int J Mol Sci 20: 2019. PMID: 31409008. DOI: $10.3390 /$ ijms20163919

31 Kleiner DE, Brunt EM, Van Natta M, Behling C, Contos MJ, Cummings OW, Ferrell LD, Liu YC, Torbenson MS, UnalpArida A, Yeh M, McCullough AJ and Sanyal AJ: Design and validation of a histological scoring system for nonalcoholic fatty liver disease. Hepatology 41: 1313-1321, 2005. PMID: 15915461. DOI: 10.1002/hep.20701

32 Kinoshita A, Onoda H, Fushiya N, Koike K, Nishino H and Tajiri H: Staging systems for hepatocellular carcinoma: Current status and future perspectives. World J Hepatol 7: 406-424, 2015. PMID: 25848467. DOI: 10.4254/wjh.v7.i3.406

33 Bauer S, Weiss TS, Wiest R, Schacherer D, Hellerbrand C, Farkas S, Scherer MN, Ritter M, Schmitz G, Schaffler A and Buechler C: Soluble CD163 is not increased in visceral fat and steatotic liver and is even suppressed by free fatty acids in vitro. Exp Mol Pathol 91: 733-739, 2011. PMID: 21839737. DOI: 10.1016/j.yexmp.2011.07.005
34 Pohl R, Haberl EM, Rein-Fischboeck L, Zimny S, Neumann M, Aslanidis C, Schacherer D, Krautbauer S, Eisinger K, Weiss TS and Buechler C: Hepatic chemerin mRNA expression is reduced in human nonalcoholic steatohepatitis. Eur J Clin Invest 47: 718, 2017. PMID: 27797398. DOI: 10.1111/eci.12695

35 Shand B, Elder P, Scott R, Frampton C and Willis J: Biovariability of plasma adiponectin. Clin Chem Lab Med 44: 1264-1268, 2006. PMID: 17032140. DOI: 10.1515/CCLM.2006.227

36 Yamashita S, Sakamoto Y, Yamamoto S, Takemura N, Omichi K, Shinkawa H, Mori K, Kaneko J, Akamatsu N, Arita J, Hasegawa K and Kokudo N: Efficacy of preoperative portal vein embolization among patients with hepatocellular carcinoma, biliary tract cancer, and colorectal liver metastases: a comparative study based on single-center experience of 319 cases. Ann Surg Oncol 24: 1557-1568, 2017. PMID: 28188502. DOI: $10.1245 / \mathrm{s} 10434-017-5800-\mathrm{z}$

37 Buechler C, Feder S, Haberl EM and Aslanidis C: Chemerin Isoforms and Activity in Obesity. Int J Mol Sci 20: 2019. PMID: 30841637. DOI: 10.3390/ijms20051128

38 Rourke JL, Dranse HJ and Sinal CJ: Towards an integrative approach to understanding the role of chemerin in human health and disease. Obes Rev 14: 245-262, 2013. PMID: 23216632. DOI: $10.1111 /$ obr.12009

39 Fulop P, Seres I, Lorincz H, Harangi M, Somodi S and Paragh G: Association of chemerin with oxidative stress, inflammation and classical adipokines in non-diabetic obese patients. J Cell Mol Med 18: 1313-1320, 2014. PMID: 24702860. DOI: $10.1111 / \mathrm{jcmm} .12282$

40 Schutte K, Schulz C, Poranzke J, Antweiler K, Bornschein J, Bretschneider $\mathrm{T}$, Arend $\mathrm{J}$, Ricke $\mathrm{J}$ and Malfertheiner $\mathrm{P}$ : Characterization and prognosis of patients with hepatocellular carcinoma (HCC) in the non-cirrhotic liver. BMC Gastroenterol 14: 117, 2014. PMID: 24990270. DOI: 10.1186/1471-230X-14117

41 Sumie S, Kawaguchi T, Kuromatsu R, Takata A, Nakano M, Satani M, Yamada S, Niizeki T, Torimura T and Sata M: Total and high molecular weight adiponectin and hepatocellular carcinoma with HCV infection. PLoS One 6: e26840, 2011. PMID: 22110596. DOI: 10.1371/journal.pone.0026840

42 Siegel AB, Goyal A, Salomao M, Wang S, Lee V, Hsu C, Rodriguez R, Hershman DL, Brown RS Jr., Neugut AI, Emond J, Kato T, Samstein B, Faleck D and Karagozian R: Serum adiponectin is associated with worsened overall survival in a prospective cohort of hepatocellular carcinoma patients. Oncology 88: 57-68, 2015. PMID: 25300295. DOI: 10.1159/ 000367971

43 Khattab MA, Eslam M, Mousa YI, Ela-adawy N, Fathy S, Shatat M, Abd-Aalhalim H, Kamal A and Sharawe MA: Association between metabolic abnormalities and hepatitis C-related hepatocellular carcinoma. Ann Hepatol 11: 487-494, 2012. PMID: 22700630.

44 Guadagni F, Roselli M, Martini F, Spila A, Riondino S, D’Alessandro R, Del Monte G, Formica V, Laudisi A, Portarena I, Palmirotta R and Ferroni P: Prognostic significance of serum adipokine levels in colorectal cancer patients. Anticancer Res 29: 3321-3327, 2009. PMID: 19661351.

45 Saetang J, Boonpipattanapong T, Palanusont A, Maneechay W and Sangkhathat S: Alteration of leptin and adiponectin in multistep colorectal tumorigenesis. Asian Pac J Cancer Prev 17, 2016. PMID: 27221946. DOI: 10.7314/apjcp.2016.17.4.2119 
$46 \mathrm{Wu}$ D, Li H, Xiang G, Zhang L, Li L, Cao Y and Zhang J: Adiponectin and its receptors in chronic hepatitis B patients with steatosis in china. Hepat Mon 13: e6065, 2013. PMID: 23914225. DOI: 10.5812 /hepatmon.6065

47 Corbetta S, Redaelli A, Pozzi M, Bovo G, Ratti L, Redaelli E, Pellegrini C, Beck-Peccoz P and Spada A: Fibrosis is associated with adiponectin resistance in chronic hepatitis $\mathrm{C}$ virus infection. Eur J Clin Invest 41: 898-905, 2011. PMID: 21539538. DOI: 10.1111/j.1365-2362.2011.02498.x

48 Korah TE, El-Sayed S, Elshafie MK, Hammoda GE and Safan MA: Significance of serum leptin and adiponectin levels in Egyptian patients with chronic hepatitis $\mathrm{C}$ virus associated hepatic steatosis and fibrosis. World J Hepatol 5: 74-81, 2013 PMID: 23646232. DOI: 10.4254/wjh.v5.i2.74

49 Baltieri L, Chaim EA, Chaim FDM, Utrini MP, Gestic MA and Cazzo E: Correlation between nonalcoholic fatty liver disease features and levels of adipokines and inflammatory cytokines among morbidly obese individuals. Arq Gastroenterol 55: 247-251, 2018. PMID: 30540086. DOI: 10.1590/S0004-2803.201800000-62

50 Arvaniti VA, Thomopoulos KC, Tsamandas A, Makri M, Psyrogiannis A, Vafiadis G, Assimakopoulos SF and Labropoulou-Karatza C: Serum adiponectin levels in different types of non alcoholic liver disease. Correlation with steatosis, necroinflammation and fibrosis. Acta Gastroenterol Belg 71: 355-360, 2008. PMID: 19317274.

51 Chen L, Liu W, Lai S, Li Y, Wang X and Zhang H: Insulin resistance, serum visfatin, and adiponectin levels are associated with metabolic disorders in chronic hepatitis $\mathrm{C}$ virus-infected patients. Eur J Gastroenterol Hepatol 25: 935-941, 2013. PMID: 23470357. DOI: 10.1097/MEG.0b013e32835fa988

52 Salman TA, Allam N, Azab GI, Shaarawy AA, Hassouna MM and El-Haddad OM: Study of adiponectin in chronic liver disease and cholestasis. Hepatol Int 4: 767-774, 2010. PMID: 21286349. DOI: 10.1007/s12072-010-9216-0
53 Gonullu G, Kahraman H, Bedir A, Bektas A and Yucel I: Association between adiponectin, resistin, insulin resistance, and colorectal tumors. Int J Colorectal Dis 25: 205-212, 2010. PMID: 19888587. DOI: 10.1007/s00384-009-0828-6

54 Nkontchou G, Bastard JP, Ziol M, Aout M, Cosson E, GanneCarrie N, Grando-Lemaire V, Roulot D, Capeau J, Trinchet JC, Vicaut $\mathrm{E}$ and Beaugrand $\mathrm{M}$ : Insulin resistance, serum leptin, and adiponectin levels and outcomes of viral hepatitis C cirrhosis. J Hepatol 53: 827-833, 2010. PMID: 20728234. DOI: 10.1016/j.jhep.2010.04.035

55 Ashktorab H, Soleimani A, Nichols A, Sodhi K, Laiyemo AO, Nunlee-Bland G, Nouraie SM and Brim H: Adiponectin, leptin, IGF-1, and tumor necrosis factor alpha as potential serum biomarkers for non-invasive diagnosis of colorectal adenoma in African Americans. Front Endocrinol (Lausanne) 9: 77, 2018. PMID: 29593647. DOI: 10.3389/fendo.2018.00077

56 Alkady MM, Abdel-Messeih PL and Nosseir NM: Assessment of serum levels of the adipocytokine chemerin in colorectal cancer patients. J Med Biochem 37: 313-319, 2018. PMID: 30598628. DOI: $10.1515 /$ jomb-2017-0062

57 Buechler C: Chemerin in liver diseases. Endocrinol Metab Syndr 3: 1-6, 2014. DOI: 10.4172/2161-1017.1000144

$58 \mathrm{Li} \mathrm{Y}$, Shi B and Li S: Association between serum chemerin concentrations and clinical indices in obesity or metabolic syndrome: a meta-analysis. PLoS One 9: e113915, 2014. PMID: 25469985. DOI: 10.1371/journal.pone.0113915
Received October 15, 2019

Revised November 22, 2019

Accepted November 28, 2019 